\title{
Editorial
}

\section{Quantitative analysis of energy markets}

\author{
Angelica Gianfreda \\ FSR, RSCAS, EUI, \\ Fiesole, Italy
}

\author{
Luigi Grossi \\ Department of Economics, \\ University of Verona, Italy
}

\section{Introduction to energy markets analysis}

In recent years, we have seen a growing interest in electricity and more generally in energy markets, due to deregulation and to increasing sensitivity towards the environment and climate change, particularly after the nuclear accident of March 2011. Electricity belongs, together with emission trading permits, to the set of commodities traded on power exchanges and over-the-counter. So just like financial markets, energy price analysis, models and forecasts have become increasingly important for both trading strategies and risk management. Consequently, research has developed in several directions, exploring models that range from economics to finance using both theoretical and quantitative analysis.

Several papers have tried to explain the economic features and implications of market structures, designs and mechanisms, of bidding systems, and of strategies to improve competition. Others have focused on financial aspects such as price modelling, forecasting, risk management and derivative pricing. Following Lemming (2004), electricity price models can be categorized according to the input data employed to estimate parameters: market prices, that is, spot, day-ahead and derivatives prices, and data on fundamentals, such as weather conditions, or supply and demand. This distinction forms the basis of two kinds of approach proposed in the literature: the first is based on stochastic differential equations borrowed from Finance and adapted for Econometric applications; the second is based on bottom-up models that describe the dynamics of fundamentals to develop a model capable of reproducing and hence predicting price dynamics.

The papers included in this special issue have been selected among those independently submitted and those presented at the International Workshop QAoEM "Quantitative Analysis of Energy Markets" held in Verona (Italy) in September 2010. All were evaluated through the journal's normal peer-review process. The papers in this special issue cover a number of topics: EUAs and their impact on the optimal policy of a competitive electricity producer; electricity price dynamics with positive and negative spikes and forecasting models; make-up clauses in gas swing contracts; the existence of a dominant producer who may exercise market power or switch across technology regimes; market integration and electricity transmission by means of market coupling; and finally oil shocks and their impact on the economic growth of oil producing countries. 


\section{Papers presented in this special issue}

\subsection{EUAs and their impact on the optimal policy of a competitive electricity producer}

Price modelling for emission credits has been concerned mostly with European Unit Allowance (EUA) prices. Mansanet-Bataller et al (2007), Convery and Redmond (2007), Alberola and Chevallier (2007, 2008) and Chevallier (2009) are among those who analyse EUA prices in a macroeconomic model. The extensive number of empirical studies on EUA prices might be due to the fact that price formation of EUAs is relatively easier to observe than other types of emission credit under the Kyoto Protocol, i.e. Certified Emission Credits (CERs) and Emission Reduction Unit (ERUs). The EUA market has been the largest international emissions trading scheme, comprising 11,000 installations such as power stations and factories, in the $27 \mathrm{EU}$ member states plus Norway, Liechtenstein and Iceland. CER and ERU markets are relatively young. CERs have been operational only since the beginning of 2006 and the first ERUs were issued in early 2008 for Joint Implementation projects commencing in 2000 onwards. Nevertheless, since the introduction of CER and ERU transferability in EU ETS, the markets for CERs and ERUs have been growing. The paper by Falbo et al. (2013-this issue) follows this literature. It contributes to the debate on the grandfathering of EUAs in the EU-ETS. It has been largely proved that grandfathering may provide an incentive to switch to more pollutant fuels, particularly for energy producer companies. The authors apply mathematical and economic models to obtain the expected profit function of an electricity generating company using fossil fuel. Expected profit includes gains deriving from selling unused carbon permits on the market. Very interestingly, they found that, under some quite general assumptions, the profit function is not monotonic in the price of EUAs. This implies that it is more profitable to produce electricity with dirty technologies and sell unused allowances. The model was applied to an Italian and a German electricity producer using different generation technologies, conventional and renewable, and led to the conclusion that high levels of grandfathering can severely bias the profit strategy of generating companies by incentivising production of electricity from polluting fuels. In any case, the analysis of German and Italian producers yielded contrasting results: in Germany it is more profitable to invest in renewables for a wider price range than in Italy. This result supports the recent energy policy of the Italian government in favour of solar plants in the national generating mix.

\subsection{Electricity price dynamics and forecasting models}

The literature on prices in deregulated markets can be divided in two broad groups: spot and forward price modelling. While in the past, forward contracts were predominant on energy markets, in recent years spot markets have become more important and many papers focus on models capable of explaining spot price formation and predicting their evolution. The papers by Fanone et al. (2013-this issue) and Bordignon et al. (2013-this issue) can be placed in this research field. In particular, the first paper deals with the issue of negative prices frequently seen in markets where alternative sources of electricity mix. The forecasting method proposed by the authors is applied to the German electricity market where the recent Renewable Energy Act gave a big boost to the introduction of renewable energy plants. One stylized fact recently observed on some electricity markets, and 
especially in Germany, is the presence of negative intra-daily spot prices. Negative prices mean that destruction of the commodity has more value than its creation: electricity is a waste product and is dumped on the market. One of the biggest issues related to variable renewable energy resources and competitive electricity market design is the potential impact of negative pricing on resource adequacy. Regions with high penetrations of variable renewable generation (e.g. wind) tend to have periods of low energy prices due to the fact that such generation has essentially a zero marginal cost (i.e. the fuel is 'free') and it is compensated for by the awarding of renewable energy credits. In fact, at certain times of the year, when renewable energy generation is high and loads are low, energy prices can and do become negative (i.e. a generator is willing to pay load to take its power). This also occurs when transmission constraints block the use of further downward control from flexible resources. The negative prices serve to establish a measure of the opportunity cost associated with a lack of dispatch flexibility. The methodological procedure proposed by the authors is based on a non-Gaussian Levy-based fractional autoregressive (FAR) process, a non-standard approach in the analysis of energy prices. The main goal of the model is to deal with negative prices and negative peaks. Price spikes frequently occur when some producers experience plant outages or when some consumers are in a period of peak consumption. The introduction of substantial amounts of intermittent power sources such as wind energy may have an impact on market prices. This proves the importance of the role of mathematicians and statisticians in the development of new tools that make it possible to explore the increasing complexity of energy markets.

The prediction of electricity prices is discussed in the paper by Bordignon et al. They apply the forecasting combination approach to half-hourly prices observed on the British market. As it is well known, deregulation of the UK electricity wholesale market dates back to 1990 when the UK government under Margaret Thatcher privatized the electricity supply industry. The authors estimate different models based on linear and nonlinear stochastic processes. Then, they combine the predictions yielded by these models using a weighting procedure previously introduced by Clemen (1989) and refined by many other authors. The paper's main contribution lies in its rigorous analysis of historical data that takes into account all the stylized facts observed on electricity prices: long term trend, mean reversion, different sources of seasonality, presence of spikes, high volatility. Secondly, the prediction strategy represents a clear reference for future works aiming at forecasting prices on deregulated markets; indeed, forecasting is becoming a crucial tool for generating companies and traders struggling daily to address the increasing uncertainty of energy markets and the corresponding volatility of spot prices.

\subsection{Make-up clauses in gas swing contracts}

The paper by Edoli et al. (2013-this issue) introduces a new mathematical pricing model for a specific clause that can be inserted in swing contracts, a very common type of long term contract used in deregulated gas markets. Swing (or fake or pay) contracts are long term (10-30 years) gas supply contracts. They allow the option holder to withdraw every day a quantity of gas subject to daily, as well as periodic (usually monthly or annual) minimum and maximum constraints. The flexibility of this contract accommodates the need to hedge frequent demand fluctuations that are in practice impossible to foresee in the long period, being linked to exogenous variables such as weather, economic circumstances, changes in 
heating technology and power production, and so on. Make-up clauses have become a very important feature of most long term gas swing deals in the last few years, and particularly since the 2008 financial crisis and the resulting oil-to-gas price decoupling. The authors show how the pricing of a swing option with make-up clauses can be reduced to a stochastic control problem. Ultimately they solve the problem by adapting appropriately the common dynamic programming algorithm. The methodological contribution of Vargiolu et al. lies in the introduction of make-up gas debt as a new state variable. This variable is then embedded in annual constraints on the state space. The computational cost is quadratic in the number of years. Price decoupling is the factor that affects contract price the most. High interest rates decrease the make-up price. The paper offers a substantial contribution to the literature because make-up clauses could potentially become a key tool with which to address the challenges of future market scenarios deriving from oil-gas price decoupling and corresponding price volatility.

\subsection{Dominant producer, market power and signals}

The recent restructuring of the electricity sector has created new opportunities and new risks, considering that previously regulators, market participants and commercial organizations managed the electricity supply in a monopolistic and highly regulated environment. Hence there is an urgent need to manage the transition towards a competitive environment. The price paid for electricity may be affected by several factors, such as generators' behaviour on the allocation of production, and transmission network congestions; as Furiò and Lucia (2009) suggest, generation, congestion and market power are strongly interdependent factors. Previous studies that focused on market power relied on oligopoly theory to simulate electricity generators' behaviour (Green and Newbery, 1992; Newbery, 1998; Wolfram, 1999); others undertook empirical research (Bask and Widerberg, 2009; Helman, 2006). At the same time, as result of market liberalization, former monopolists enjoy significant market power. Hence Vespucci et al. (2013-this issue) consider the existence of a dominant producer in a liberalized electricity market characterized by geographical zones interconnected by capacity-constrained transmission lines. They propose a model to account for the dominant producer's optimal bidding strategies, optimal resource scheduling in the medium-long term and the market clearing process. The aim of describing the dominant producer's behaviour is achieved by introducing a 'mixed integer linear programming' model, where mixed integer linear constraints and piece-wise linear functions are used to define complementarity conditions and revenue terms, with the final aim of computing the global solution in a two-stage procedure. The first step is mainly devoted to computations of hourly zonal prices given under the assumption of perfect competition, given hourly zonal demands and producers' hourly bids at plant level. In the second step, the authors identify hours during which the dominant player can exercise market power, thereby increasing his profits and modifying the optimal solution previously achieved by perfect competition. In solving the clearing of the market, the authors consider the interrelationships between the dominant producer's hourly production decisions and hourly zonal prices.

The strategic behaviour of generators may result in production allocations that can directly affect final prices paid for electricity. Zachmann (2013-this issue) presents a new model for electricity prices, reproducing the merit order criterion for markets dominated by thermal 
units and identifying a non-linear relationship between electricity and fundamental drivers such as coal and natural gas, as well as carbon emission allowances. Specifically, he proposes a regime model for electricity spot prices that allows switching between producing technologies, and hence accounts for costs and emissions levels. In this way, the electricity price is defined as a nonlinear combination of fuel and carbon prices, differentiated across four identified regimes, with important implications for market efficiency, price forecasting and market power monitoring. Indeed, if electricity prices are not affected by fuel and carbon prices in a thermal dominated market, market pricing will not be based on marginal costs; in addition, the predictability of fundamental drivers could help in understanding when market power has an impact on final electricity prices.

\subsection{Market integration: regulation, transmission, and auctioning}

Competitiveness, sustainability and energy supply security are essential issues in the pursuit of European energy market integration and the creation of a single energy area (European Commission, 2007). To achieve this aim, there is an urgent need to upgrade transmission network capacity to allow electricity generated in one country to be transferred and consumed in another country; at the same time, increasing shares of renewable intermittent generation will require additional management.

Energy markets were initially liberalized autonomously at a national level, with domestic scope, but there has been a growing need for an optimal management of cross-border transmissions and congestions. And indeed, economic assessment of the interconnectors required to transfer electricity between two neighbouring locations has been studied by Cartea and González-Pedraz (2012); whereas Tangerås (2012) investigates the optimality of vesting regulatory power in a single supranational authority, since arguably a single regulator may be unable to manage the entire network. The author also demonstrates that optimal network governance of a centralized authority depends on the balance of different interests across countries. Apart from common regulations, market functioning in terms of competition among producers can be obstructed by limited transmission capacity at the borders of interconnected markets. Therefore two mechanisms have been put forward to solve the allocation of such scarce cross-border capacity: the first is implicit auctioning, and the second is coordinated explicit auctioning, proposed by the European Transmission System Operators (ETSO) but not yet implemented.

The latter system will allow countries to keep their power exchanges running, but if it is found to be less efficient than of the former system when it is not coordinated. This conclusion was reached by Jullien et al. (2012) who studied the European competitive oligopoly by analysing energy prices and transmission capacity allocations. They also propose designing a secondary market for used transmission capacity to solve the problem. Nevertheless, there is no clear consensus on the two mechanisms. On one side, the inadequacy of explicit auctioning has been demonstrated in terms of increasing price spreads (see among others Creti et al., 2010; Kristiansen, 2007); ambiguous results on price convergence (see respectively Zachmann, 2008; Bunn and Gianfreda, 2010); and in exercising market power, as in Bunn and Zachmann (2010). On the other side, it has been shown that implicit auctioning, intended as a mechanism to eliminate cross-border inefficiencies by including arbitrage opportunities in auctions at individual power exchanges, produces welfare maximizations on some occasions (see Bohn et al., 1983) and on others does not reduce welfare (Chao and Peck, 1996). Similarly, some authors show that such a 
mechanism reduces market power (for instance Parisio and Bosco, 2008) whereas others show the opposite (Hobbs et al., 2005). The implicit auction mechanism adapted in Europe is designed to include cross-border trades in the day-ahead action mechanisms on individual power exchanges to avoid inefficiency. Hence, Meeus (2011) studies and compares three different implementations of the implicit auction mechanism (no coupling, volume coupling and one way price coupling) on the Kontek Cable interconnecting East Denmark with Germany; he shows empirically that the one way price coupling performs better than the other two mechanisms. Other successful examples of implicit auctioning with price coupling systems are those within the Nordic area, those between Spain and Portugal, and those between France, Belgium and the Netherlands.

Nevertheless, a new result is presented by Oggioni and Smeers (2013-this issue). The authors analyse and simulate market coupling in a network of six nodes previously described in the literature, and a market split into two zones, assuming different zonal decompositions, coordination of transmission system operators, and a lack of strategic behaviours. Implementing a generalized Nash equilibrium and social welfare in a basic model with one single settlement for energy, transmission markets and congestion costs directly affecting electricity prices, they observe that market coupling can be weak and propose a benchmark for market efficiency using the nodal pricing system developed in US but not in European markets. Oggioni and Smeers initially consider a situation of perfect integration of TSOs, showing that the right combination of market coupling with countertrading can be efficient compared to nodal pricing, whereas inadequate levels of transfer capacity can degrade welfare. Their analysis and the phenomena they observe could be extended to a multi-zone markets that better represent reality, with expectations of decreasing capacity coupled with increasing congestion costs.

\subsection{Oil, dependency on oil and potential implications}

In recent years, market analysts, researchers, policy makers and regulators have been carefully considering issues related to security of supply, diversification of the energy mix and investments in renewables to reduce carbon emissions and mitigate climate change. Therefore agricultural as well as energy commodities have attracted increasing interest, given the ultimate aim of substituting or reducing market dependency on oil. However, after the devastating nuclear accident in Japan of March 2011, replacement of polluting technologies based on coal and oil no longer seems so easy in the light of the sudden setback in the nuclear renaissance, technical problems related to intermittent generating capacity, and the serious repercussions on food markets of the biofuels boom. Therefore, few papers have considered the various aspects of market dependency on oil, focusing rather on sudden price changes and hence testing the effects of oil shocks. Generally speaking, the effects of market dependency on oil can affect the formation of agents' beliefs when a general equilibrium model for macroeconomic variables is considered, given that the oil prices influence, through a learning process, both production and consumption and hence aggregate supply and demand curves, as in Milani (2009). Approaching the issue from an international perspective, and so in terms of effects across markets, trades or imports and exports across countries can also be reduced by oil prices shocks and in general oil price volatility ( see Chen and Hsu, in press). The dynamics of stock prices can also be affected as shown by Zhu et al. (2011) in OECD and non-OECD countries. Conversely, in the industrial sector, Elyasiani et al. (2011) provide evidence on how variations in oil returns produce 
excess stock returns in US industries, whereas Basher et al. (2012) study the dynamic relationships between oil prices, exchange rates and stock prices in emerging markets.

In terms of the effects within a single market, interrelations between GDP growth and inflation have been investigated in Spain (Gómez-Loscos et al., 2011), in Japan (Zhang, 2008); and also in Greece, where real economic activities and employment have been also explored (Papapetrou, 2001). Farzanegan (2011) analyses the implications of oil shocks on Iranian governmental expenditures, showing on one side that expenditures on military and security budgets react significantly, while on the other side social expenditures seem to be unaffected. When oil producing markets are considered, researchers have tried to understand the relations between oil shocks and internal business cycles by providing evidence on the inverse relation between (high) natural resources and (low) economic growth (see among others Sachs and Warner, 2001). In this context, Cologni and Manera (2013-this issue) try to answer the important question of how oil shocks affect economic activities, and especially the impact of fiscal policy on consumption, investments and labor markets. More specifically, they provide evidence of the effects of oil shocks on the economic growth of the Gulf Cooperation Council oil producing countries. The authors specifically look at reallocation between private and public sectors caused by government fiscal policy; in the case of the public sector the authors allow for several aspects of spending policy, such as purchases, investments, and compensations. They therefore propose a theoretical framework based on a real business cycle model of macroeconomic activity to detect and explain sectorial reallocations following wealth effects induced by oil perturbations and fiscal policy. In detail, a neoclassical growth model is considered together with preferences, technologies, resource constraints and rules for public finance, where households, firms and the government are assumed to interact in perfect competition. The analysis, implemented both on annual data referring to Bahrain, Kuwait, Oman, Qatar, the United Arab Emirates and the Kingdom of Saudi Arabia for the period from 1994 to 2009, and simulation results, show that oil price shocks can have negative wealth effects on the private sector whereas wealth effects become positive in the public sector with the shift of productive factors from households and firms to government sectors.

\section{Concluding remarks}

We hope that these papers will contribute to advance research and analysis of energy markets by stimulating discussion and suggestions on the topics presented.

\section{Acknowledgements}

We would like to thank the Editors-in-Chief for the opportunity to publish this special issue, especially Richard Tol for his invaluable support; the authors who have contributed and all the referees for their effort. The support of the Robert Schuman Centre, and the Florence School of Regulation is kindly acknowledged by the first guest editor. Luigi Grossi's work on the project was partially supported by MIUR grant, PRIN08.

\section{References}

Alberola, E.J., Chevallier, B. Cheze, 2007. European carbon prices fundamentals in 2005- 
2007: the effects of energy markets, temperatures \& sectorial production. Document deTravail working paper, pp. 2007-2033.

Alberola, E.J., Chevallier, B. Cheze, 2008. Price drivers and structural breaks in European carbon prices 2005-2007. Energy Policy 36 (2), 787-797.

Basher, S.A., Haug, A.A., Sadorsky, P., 2012. Oil prices, exchange rates and emerging stock markets. Energy Economics 34 (1), 227-240.

Bask, M., Widerberg, A., 2009. Market structure and the stability and volatility of electricity prices. Energy Economics 31, 278-288.

Bohn, R.E., Caramanis, M.C., Schweppe, F.C., 1983. Optimal pricing in electrical networks over space and time. RAND J. Economics 15 (3), 360-376.

Bordignon, S., Bunn, D.W., Lisi, F., Nan, F., 2013. Combining day-ahead forecasts for British electricity prices. Energy Economics 35, 88-103 .

Bunn, D.W., Gianfreda, A., 2010. Integration and shock transmissions across European electricity forward markets. Energy Economics 32 (2), 278-291.

Bunn, D.W., Zachmann, G., 2010. Inefficient arbitrage in inter-regional electricity transmission. Journal of Regulatory Economics 37, 243-265.

Cartea, Á., González-Pedraz, C., 2012. How much should we pay for interconnecting electricity markets? A real options approach. Energy Economics 34 (1), 14-30.

Chao, H.P., Peck, S., 1996. A market mechanism for electric power transmission. Journal of Regulatory Economics 10 (1), 25-60.

Chen, S.S., Hsu, K.W., (in press), Reverse globalization: Does high oil price volatility discourage international trade?, Energy Economics, Corrected Proof, Available online 11 February 2012. http://dx.doi.org/10.1016/i.eneco.2012.01.005.

Chevallier, J., 2009. Carbon futures and macroeconomic risk factors: a view from the EUETS. Energy Economics 31 (4), 614-625.

Clemen, R.T., 1989. Combining forecasts: a review and annotated bibliography. International Journal of Forecasting 5, 559-583.

Cologni, A., Manera, M., 2013. Exogenous Oil Shocks. Fiscal Policies and Sector Reallocations in Oil Producing Countries, Energy Economics 35, 42-57 .

Convery, F.J., Redmond, L., 2007. Market and price developments in the European Union emissions trading scheme. Rev. Environ. Economics Policy 1 (1), 88-111.

Creti, A., Fumagalli, E., Fumagalli, E., 2010. Integration of electricity markets in Europe: relevant issues for Italy. Energy Policy 38 (11), 6966-6976. 
Edoli, E., Fiorenzani, S., Ravelli, S., Vargiolu, T., 2013. Modeling and valuing make-up clauses in gas swing contracts. Energy Economics 35, 58-73 .

Elyasiani, E., Mansur, I., Odusami, B., 2011. Oil price shocks and industry stock returns. Energy Economics 33 (5), 966-974.

European Commission, 2007. An energy policy for Europe, COM(2007)1 final.

Falbo, P., Felletti, D., Stefani, S., 2013. Free EUAs and fuel switching. Energy Economics 35, 14-21 .

Fanone, E., Gamba, A., Prokopczuk, M., 2013. The case of negative day-ahead electricity prices. Energy Economics 35, 22-34.

Farzanegan, M.R., 2011. Oil revenue shocks and government spending behavior in Iran. Energy Economics 33 (6), 1055-1069.

Furiò, D., Lucia, J.J., 2009. Congestion management rules and trading strategies in the Spanish electricity market. Energy Economics 31, 48-60.

Gómez-Loscos, A., Montañés, A., Gadea, M.D., 2011. The impact of oil shocks on the Spanish economy. Energy Economics 33 (6), 1070-1081.

Green, R.J., Newbery, D.M., 1992. Competition in the British Electricity Spot Market. Journal of Political Economics 100 (5), 929-953.

Helman, U., 2006. Market power monitoring and mitigation in the US wholesale power markets. Energy 31, 877-904.

Hobbs, B.F., Rijkers, F.A.M., Boots, M.G., 2005. The more cooperation, the more competition? A Cournot analysis of the benefits of electric market coupling. Energy Journal. $26(4), 69-97$.

Jullien, C., Pignon, V., Robin, S., Staropoli, C., 2012. Coordinating cross-border congestion management through auctions: an experimental approach to European solutions.

Energy Economics 34 (1), 1-13.

Kristiansen, T., 2007. An assessment of the Danish-German cross-border auctions.

Energy Policy 35 (6), 3369-3382.

Lemming, G., 2004. Price Modelling for Profit at Risk Management. In: Bunn, D. (Ed.), Modelling prices in competitive electricity markets. John Wiley \& Sons, Ltd., pp. 287-306.

Mansanet-Bataller,M., Pardo, A., Valor, E., 2007. CO2 prices, energy and weather. Energy Journal 28 (3), 67-86. 
Meeus, L., 2011. Implicit auctioning on the Kontek Cable: third time lucky? Energy Economics 33 (3), 413-418.

Milani, F., 2009. Expectations, learning, and the changing relationship between oil prices and the macroeconomy. Energy Economics 31 (6), 827-837.

Newbery, M.D., 1998. Competition, contracts, and entry in the electricity spot market. RAND J. Economics 29 (4), 726-749.

Oggioni, G., Smeers, Y., 2013. Market failures of Market Coupling and Counter-Trading in Europe: an Illustrative Model Based Discussion. Energy Economics 35, 74-87 .

Papapetrou, E., 2001. Oil price shocks, stock market, economic activity and employment in Greece. Energy Economics 23 (5), 511-532.

Parisio, L., Bosco, P., 2008. Electricity prices and cross-border trade: volume and strategy effects. Energy Economics 30 (4), 1760-1775.

Sachs, J.D., Warner, A.M., 2001. The curse of natural resources. Eur. Economics Rev. 45, 827-838.

Tangerås, T.P., 2012. Optimal transmission regulation of an integrated energy market. Energy Economics 34 (5), 1644-1655.

Vespucci, M.T., Innorta, M., Cervigni, G., 2013. A Mixed Integer Linear Programming Model of a Zonal Electricity Market with a Dominant Producer. Energy Economics 35, 35-41

Wolfram, C.D., 1999. Measuring duopoly power in the British electricity spot market. Am. Economics Rev. 89 (4), 805-826.

Zachmann, G., 2008. Electricity wholesale market prices in Europe: convergence? Energy Economics 30 (4), 1659-1671.

Zachmann, G., 2013. A Stochastic Fuel Switching Model for Electricity Prices. Energy Economics 35, 5-13.

Zhang, D., 2008. Oil shock and economic growth in Japan: a nonlinear approach. Energy Economics 30 (5), 2374-2390.

Zhu, H.M., Li, S.F., Yu, K., 2011. Crude oil shocks and stock markets: a panel threshold cointegration approach. Energy Economics 33 (5), 987-994. 